\title{
Causes of Interannual-Decadal Variability in the Meridional Overturning Circulation of the Midlatitude North Atlantic Ocean
}

\author{
Arne Biastoch, Claus W. Böning, and Julia GetzlafF \\ Leibniz-Institut für Meereswissenschaften, Kiel, Germany \\ JeAn-Marc Molines \\ Laboratoire des Ecoulements Géophysiques et Industriels, Grenoble, France \\ GURVAN MADEC \\ Laboratoire d'Océanographie et du Climat: Expérimentation et Approches Numérique, Paris, France
}

(Manuscript received 4 January 2008, in final form 9 June 2008)

\begin{abstract}
The causes and characteristics of interannual-decadal variability of the meridional overturning circulation (MOC) in the North Atlantic are investigated with a suite of basin-scale ocean models [the Family of Linked Atlantic Model Experiments (FLAME)] and global ocean-ice models (ORCA), varying in resolution from medium to eddy resolving $\left(1 / 2^{\circ}-1 / 12^{\circ}\right)$, using various forcing configurations built on bulk formulations invoking atmospheric reanalysis products. Comparison of the model hindcasts indicates similar MOC variability characteristics on time scales up to a decade; both model architectures also simulate an upward trend in MOC strength between the early 1970s and mid-1990s. The causes of the MOC changes are examined by perturbation experiments aimed selectively at the response to individual forcing components. The solutions emphasize an inherently linear character of the midlatitude MOC variability by demonstrating that the anomalies of a (non-eddy resolving) hindcast simulation can be understood as a superposition of decadal and longer-term signals originating from thermohaline forcing variability, and a higher-frequency wind-driven variability. The thermohaline MOC signal is linked to the variability in subarctic deep-water formation, and rapidly progressing to the tropical Atlantic. However, throughout the subtropical and midlatitude North Atlantic, this signal is effectively masked by stronger MOC variability related to wind forcing and, especially north of $30^{\circ}-35^{\circ} \mathrm{N}$, by internally induced (eddy) fluctuations.
\end{abstract}

\section{Introduction}

There has been much attention in recent years on determining the state and possible changes in the meridional overturning circulation (MOC) of the North Atlantic Ocean. The MOC effectively comprises the northward flow of upper-layer warm tropical water by the Gulf Stream system and its southward return by the deep western boundary current (DWBC). Because of the marked temperature contrast between the upper and lower branches, the MOC formally represents the main agent for the northward transport of heat in the

Corresponding author address: Dr. Arne Biastoch, LeibnizInstitut für Meereswissenschaften, Düsternbrooker Weg 20, 24105 Kiel, Germany.

E-mail: abiastoch@ifm-geomar.de subtropical-midlatitude North Atlantic (Roemmich and Wunsch 1985; Talley 2003); MOC transport changes are hence implicated in observed multidecadal variations of large-scale sea surface temperature distribution (Latif et al. 2006) and climate indices (Knight et al. 2005).

Interest in the Atlantic MOC has been stimulated by the prospect of its gradual weakening during the twenty-first century, as suggested by the climate model scenarios compiled for the third and fourth Intergovernmental Panel on Climate Change (IPCC) assessment reports (Houghton et al. 2001; Meehl et al. 2007), and as a consequence of reduced deep-water formation due to anthropogenic warming trends in the subarctic Atlantic (Gregory et al. 2005). Detecting such a gradual anthropogenic trend in the MOC transport poses a formidable challenge for the design of observing systems 
(Hirschi et al. 2003). Of particular concern is that a low-frequency MOC "signal" related to subarctic water mass transformation may be blurred by a broad spectrum of "noise," such as higher-frequency fluctuations related to local wind forcing or internal ocean dynamics (e.g., Baehr et al. 2004). The objective of this study is to contribute to unraveling the characteristics and dynamical causes of midlatitude MOC variability on interannual-decadal time scales by using a sequence of experiments with regional and global ocean models.

Present understanding of MOC variability on various time scales derives from a variety of observational and modeling studies. The role of local wind forcing on short time scales compared to the baroclinic adjustment time involving cross-basin Rossby wave propagation, that is, especially in the (intra-) seasonal range, was first noted by Bryan (1982), followed up by Böning and Herrmann (1994) and Jayne and Marotzke (2001): its main elements are changes in meridional Ekman transport at the surface, compensated by a weakly depthdependent return flow below, which tends to become concentrated near the western boundary. Further affected by strong mesoscale eddy signals, such highfrequency fluctuations are found to dominate transport records, for example, in DWBC measurements off Newfoundland (Schott et al. 2006) and the Bahamas (Lee et al. 1990), or in the MOC time series inferred from the transoceanic Rapid Climate Change (RAPID) array along $25^{\circ} \mathrm{N}$ (Cunningham et al. 2007).

Observational derivations of meridional transport variability on interannual and longer time scales are scarce and partly inconclusive as yet. While Bryden et al. (2005) noted a 30\% decline in their MOC estimates based on transoceanic section repeats along $26.5^{\circ} \mathrm{N}$, inverse calculations for a repeatedly occupied section along $48^{\circ} \mathrm{N}$ gave no evidence for significant MOC changes of more than $\pm 3 \mathrm{~Sv}\left(1 \mathrm{~Sv} \equiv 10^{6} \mathrm{~m}^{3} \mathrm{~s}^{-1}\right)$ during the 1990s (Lumpkin et al. 2008); a similar conclusion was drawn by Schott et al. (2006) in comparing DWBC transports at that latitude between measurement periods during 1999-2005 and 1993-95. This appears consistent with the magnitude $[O(10 \%-20 \%)$ of the mean] of the MOC variability that has been a typical result of ocean model integrations using atmospheric forcing based on atmospheric reanalysis data (Häkkinen 1999; Eden and Willebrand 2001; Gulev et al. 2003; Beismann and Barnier 2004; Bentsen et al. 2004; Bailey et al. 2005; Böning et al. 2006).

As suggested by these model hindcasts a main factor determining the MOC variability on decadal time scales is the intensity of deep wintertime convection in the Labrador Sea. Variations in the hydrographic properties in the subpolar North Atlantic as a consequence of changes in the convective intensity are well established (Curry et al. 1998; Visbeck et al. 2003), and appear linked predominantly to the large-scale atmospheric conditions, especially the heat fluxes associated with the North Atlantic Oscillation (NAO). However, whereas a variety of tracer data has illuminated the spreading of the Labrador seawater (LSW) variability signatures along the DWBC to $26^{\circ} \mathrm{N}$ (Molinari et al. 1998 ) and into the interior subtropical ocean (Curry et al. 1998), inferences of the dynamical effect of this variability on the MOC are presently based on model studies only. Mechanisms that may bear on the response of the basin-scale MOC include a fast exit pathway for a significant fraction of newly formed LSW (Brandt et al. 2007); associated with that, a dynamical reaction of the deep boundary current in the Labrador Sea within a year (Böning et al. 2006) and after about $2 \mathrm{yr}$ at the exit of the subpolar basin off the Grand Banks of Newfoundland (Eden and Greatbatch 2003); and a rapid equatorward communication of the MOC signal established there via fast boundary wave processes (Johnson and Marshall 2002; Getzlaff et al. 2005).

Whereas there is presently no way of assessing model simulations against directly observed MOC records, some indirect inference can be drawn concerning multidecadal MOC trends: a typical feature of all model hindcasting studies driven by atmospheric reanalyses fields is an increasing trend of the MOC by about 2-4 $\mathrm{Sv}$ from lowest values in the late 1960s or early 1970 s to a maximum in the mid-1990s, corresponding to the increasing trend in the NAO index over this period. This feature of the model simulations was found consistent with the upward trend in the basin-scale MOC strength inferred from observed interhemispheric SST anomaly patterns (Latif et al. 2006).

The response of the MOC to changes in subarctic deep-water formation may be affected by processes that are difficult to capture in model simulations and represented with limited and varying realism in different model configurations. An aspect of particular concern is the representation of the (sub-) mesoscale flow features that govern, for example, the exchanges between the deep-water formation sites and the boundary currents (Houghton and Visbeck 2002; Eden and Böning 2002; Brandt et al. 2004; Chanut et al. 2008) and the equatorward transmission of variability signals along the western boundary (Getzlaff et al. 2005). Another aspect is the representation of the outflows of dense waters from the Nordic seas. In the present climate, the overflows provide the densest source waters to the deep southward branch of the MOC. Model studies have pointed to the role of this dense water source as a stabilizing factor for the MOC in its response to LSW 
formation changes (Döscher and Redler 1997), including its response to a possible collapse of deep convection in global warming scenarios (Wood et al. 1999), and to the leading role of changes in overflow conditions for the MOC evolution on longer time scales (Schweckendiek and Willebrand 2005): this suggests the potential importance of a correct representation of the effect of the processes governing the density evolution of the outflows, such as the small-scale entrainment processes in the bottom boundary layer of the downslope flow (Girton and Sanford 2003).

The objectives of this study are to contribute to an understanding of the various causes determining the MOC variability in midlatitude and subtropical North Atlantic, with a focus toward identifying the signatures of changes in subarctic deep-water formation. To assess the impact of model compromises in the simulation of (sub-) mesoscale processes, we adopt a set of both basin-scale and global models: because of the range of resolutions (from $1 / 2^{\circ}$ to $1 / 12^{\circ}$ ) and, accordingly, parameterizations for subgrid-scale mixing, the model solutions show some strong differences in the mean MOC, providing us with an important means to test the forcing mechanisms, in particular the robustness of the MOC response to forcing variations. The model simulations include hindcast runs driven by atmospheric conditions over the last five decades, complemented by a set of numerical experiments targeted at the response to artificial perturbations in the surface boundary conditions to elucidate the role of the various forcing mechanisms, in particular the relative role of winddriven and internally generated variability versus effects of thermohaline forcing in the subarctic Atlantic.

The paper is organized as follows: section 2 describes the used model setups; general aspects and the correlation of MOC and heat transport are discussed in section 3. Section (4) examines the low-frequency characteristics with respect to its robust behavior across model resolutions and systems; then the forcing is split into its individual wind and thermohaline causes (section 5). Section 6 closes the paper with discussion and summary.

\section{Model configurations}

The study utilizes two sets of different $z$-coordinate models: regional implementations of the Modular Ocean Model (MOM2; Pacanowski 1996) for the Atlantic Ocean and global configurations (ORCA) of the Nucleus for European Modeling of the Ocean (NEMO; Madec 2006) coupled to the Louvain-la-Neuve Ice Model version 2 (LIM2) sea ice model (Fichefet and Morales Maqueda 1999). The ORCA version used here is part of a model hierarchy developed as part of the European model collaboration Drakkar (Drakkar Group 2007).

\section{a. Atlantic models}

The first set of experiments are part of the Family of Linked Atlantic Model Experiments (FLAME; Böning et al. 2003; Beismann and Redler 2003), a hierarchy of Atlantic Ocean models. All members share the same model code, a refined version of MOM2, and use the same 45 levels in the vertical with level thicknesses ranging from $10 \mathrm{~m}$ at the surface to a constant $250 \mathrm{~m}$ below 2250-m depth, but differ in horizontal resolution and subgrid-scale mixing parameterizations: (1) a "medium resolution" Atlantic configuration $\left(70^{\circ} \mathrm{N}-70^{\circ} \mathrm{S}\right)$ with an isotropic resolution of $13^{\circ} \times 1 / 3^{\circ} \cos \phi(\phi$ latitude), and (2) a North Atlantic configuration $\left(70^{\circ} \mathrm{N}-\right.$ $18^{\circ} \mathrm{S}$ ) with $1 / 12^{\circ} \times 1 / 12^{\circ} \cos \phi$ as a "high resolution" equivalent. The medium resolution appears to be an ideal compromise between the need to resolve the boundary currents, especially in the deep-water formation area of the subpolar North Atlantic, and the need to perform an extensive set of sensitivity experiments.

Both models share the same northern boundary at $70^{\circ} \mathrm{N}$, but with different implementations. The coarse configuration follows the setup developed in the Dynamics of North Atlantic Models (DYNAMO) project (Willebrand et al. 2001), where the effect of water mass conversion in the Nordic seas north of the closed boundary is mimicked by a damping of temperature and salinity to climatological conditions. The highresolution version builds on the model of Eden and Böning (2002), but has an open northern boundary where temperature and salinity $(T-S)$ values for inflow points are taken from the same climatology as above, while the barotropic flow is given by the results of an Arctic Ocean model (Brauch and Gerdes 2005). At $18^{\circ} \mathrm{S}$ similar $T-S$ conditions have been applied, the barotropic flow is calculated from the wind field using the Sverdrup relation with a transition toward the western boundary.

The coarse-resolution model spans the Atlantic to $70^{\circ} \mathrm{S}$, with open boundaries in the Drake Passage and south of Africa $\left(30^{\circ} \mathrm{E}\right)$, where streamfunction data for the external mode are prescribed from the Semtner and Chervin (1992) model (Drake Passage) and from the Agulhas model of Biastoch and Krauss (1999). The Strait of Gibraltar is closed in the coarse-resolution model, the effect of the outflow incorporated by a damping toward climatological conditions in the Gulf of Cadiz; whereas in the high-resolution model the western Mediterranean (up to $16^{\circ} \mathrm{E}$, with a damping 
TABLE 1. FLAME model experiments.

\begin{tabular}{lccll}
\hline & Resolution & \multicolumn{1}{c}{ Period } & \multicolumn{1}{c}{ Wind forcing } & \multicolumn{1}{c}{ Heat forcing } \\
\hline F_CLIM & $13^{\circ}$ & $1900-57$ & ECMWF climatology & ECMWF climatology \\
F_REF & $13^{\circ}$ & $1958-2001$ & ECMWF climatology + NCEP anomalies & ECMWF climatology + NCEP anomalies \\
F_HEAT & $13^{\circ}$ & $1958-2001$ & ECMWF climatology & ECMWF climatology + NCEP anomalies \\
F_HIGH-RES & $1 / 1^{\circ}$ & $1987-2004$ & ECMWF climatology + NCEP anomalies & ECMWF climatology + NCEP anomalies \\
\hline
\end{tabular}

toward climatology near the boundary) and, thus the exchange through the straits is included explicitly.

Subgrid-scale mixing of tracers is parameterized by isopycnal diffusion; the effect of unresolved eddies on tracer advection in the coarse version additionally uses the parameterization of Gent and McWilliams (1990) $\left(\kappa=200 \mathrm{~m}^{2} \mathrm{~s}^{-1}\right)$. Viscosity is parameterized by a biharmonic (harmonic) operator for the $1 / 12^{\circ}\left(1 / 3^{\circ}\right)$ model. For a better representation of the density evolution in the Nordic seas outflows, the bottom boundary layer parameterization (BBL) of Beckmann and Döscher (1997) is used in both model versions. Surface boundary layer dynamics, that is, the effect of wind fluctuations on the mixed layer depth, are simulated by a simple Kraus and Turner (1967) scheme.

The models were started from rest, initialized by a mean Levitus $T-S$ field. The medium-resolution version $\left(1 / 3^{\circ}\right)$ was spun up for $25 \mathrm{yr}$; after that a $100-\mathrm{yr}$ (1900-2001) run was performed where the monthly wind stress and heat flux forcing during the first $58 \mathrm{yr}$ followed the formulation of Barnier et al. (1995), based on monthly-mean European Centre for Medium-Range Weather Forecasts (ECMWF) products from 1986 to 1988 (experiment F_CLIM; see Table 1). To avoid artificial shifts to a different mean state monthly anomalies from the National Centers for Environmental Prediction-National Center for Atmospheric Research (NCEP-NCAR) reanalysis dataset (Kalnay et al. 1996) have been calculated for the years 1958-2001 relative to the ECMWF climatology, and used to vary the surface forcing interannually ( $\left.F_{-} R E F\right)$; here, the formulation of the heat flux was chosen to follow that developed by Eden and Willebrand (2001). In all model cases, sea surface salinity (SSS) is restored to the monthly Levitus climatology using a time scale of 30 days; no explicit freshwater fluxes are applied.

To elucidate the relative effects of the variability in wind and heat flux forcing, F_REF is complemented by a perturbation experiment (F_HEAT) in which the interannually varying forcing for 1958-2001 was artificially restricted to the heat flux, whereas the monthlymean ECMWF climatology of F_CLIM was used for the wind stress forcing.

The high-resolution $\left(1 / 12^{\circ}\right)$ model was spun up for 10 yr using the same climatological forcing. After that the period 1987-2004 was simulated (F_HIGH-RES) by adding NCEP anomalies.

\section{b. Global model}

To test the robustness of the findings based on FLAME a companion set of experiments has been performed with a global ocean [Océan Parallélisé (OPA)] sea ice (LIM) model (Madec 2006). The quasi-isotropic tripolar grid (Madec and Imbard 1996) that avoids the North Pole singularity has a nominal resolution of $1 / 2^{\circ}$ at the equator; the configuration is referred to as ORCA05. With a gridcell size between 30 and $50 \mathrm{~km}$ at midlatitudes, the resolution is slightly coarser than the $1 / 3^{\circ}$ FLAME model. As in FLAME a Gent and McWilliams (GM) scheme (Gent and McWilliams 1990) is adopted $\left(\kappa=1000 \mathrm{~m}^{2} \mathrm{~s}^{-1}\right)$ to parameterize the effect of subgrid-scale eddy processes. Since it effectively acts to flatten isopycnals, thus mimicking baroclinic instability and reducing the mean potential energy, the parameterization implies a suppression of mesoscale eddy activity in the models. In the vertical 46 levels (with 10 levels in the upper $100 \mathrm{~m}$ and $250-\mathrm{m}$ resolution at depth) are used, whereby the bottom cells are allowed to be partially filled. The better representation of topographic slopes in combination with a refined, energyand enstrophy-conserving advection scheme (an adaptation of Arakawa and Lamb 1981) were found to led to marked improvements in various circulation features (Barnier et al. 2006; Le Sommer et al. 2008).

The surface boundary conditions used for the present ORCA simulations are based on the atmospheric datasets and formulations developed by Large and Yeager (2004) for global ocean-ice models; these have been suggested as a basic choice for the design of "coordinated ocean-ice reference experiments (COREs)" (Griffies et al. 2008). The daily forcing datasets are based on a combination of NCEP-NCAR reanalysis products for the years 1958-2004 with various satellite datasets and involve adjustments that correct global imbalances (e.g., produce near-zero global mean heat and freshwater fluxes when used in combination with observed SSTs). Turbulent fluxes are computed from bulk formulas as a function of the prescribed atmospheric 
TABLE 2. ORCA model experiments.

\begin{tabular}{lcccc}
\hline \hline & Period & Wind forcing & Heat forcing & Freshwater forcing \\
\hline O_CLIM & $0-66$ & CORE climatology & CORE climatology & CORE climatology \\
O_REF & $1958-2000$ & CORE interannual & CORE interannual & CORE interannual \\
O_WIND & $1958-2000$ & CORE interannual & CORE climatology & CORE climatology \\
O_HEAT + SALT & $1958-2000$ & CORE climatology & CORE interannual & CORE interannual \\
O_HEAT & $1958-2000$ & CORE climatology & CORE interannual & CORE climatology \\
\hline
\end{tabular}

state and the simulated ocean surface state (SST and surface currents).

The model configurations differ also with respect to the haline forcing: in all FLAME cases SSS is rather strongly damped (30-day time scale) toward the monthly climatological values of Levitus and Boyer (1994), and effects of freshwater flux anomalies are not considered. ${ }^{1}$ In contrast, the surface boundary condition in ORCA is formulated in terms of freshwater fluxes, using the CORE datasets for the time-varying atmospheric variables and river runoff. However, since even small errors in the freshwater budget are prone to lead to unacceptable drifts in (uncoupled) global model integrations (see, e.g., the discussion in Griffies et al. 2008) we follow the common practice of damping SSS toward monthly-mean climatological values, adopting, however, a configuration with a much weaker (time scale of 180 days) relaxation of SSS than in previous studies. Test integrations showed that an artificial drift in the MOC could be minimized by preventing spurious salinity drifts in the polar water masses. This could be by either imposing a "strong" (time scales of 30 days) relaxation of SSS or by a "weak" relaxation (180 days) of temperature and salinity in the water column of the polar oceans. For the sake of retaining a less perturbed seasonal surface freshwater and sea ice cycle than in the approach with stronger surface restoring, we here chose the second option, ${ }^{2}$ that is, we adopted a "robust diagnostic" configuration for the Arctic (north of $70^{\circ} \mathrm{N}$ ) and the Southern Ocean (south of $50^{\circ} \mathrm{S}$, for the same reasons). By choosing this approach it is clear that our main focus is on the effects outside the polar latitudes, that is, the subpolar North Atlantic that is not affected by the restoring. We note, however, that the damping of Arctic anomalies implies that in the present global model setup, the water mass properties of the outflows

\footnotetext{
${ }^{1}$ Eden and Willebrand (2001) have examined the effect of adding freshwater flux anomalies derived from reanalysis products but found them of negligible importance in a coarse-resolution FLAME configuration.

${ }^{2}$ An additional experiment, using the first option with a strong SSS restoring has eluded a weaker variability of the MOC, especially in the subpolar North Atlantic.
}

from the Nordic seas (i.e., the northern "boundary" of the domain of interest to the present study) are, as in FLAME, kept close to the climatological mean conditions: in other words, possible MOC changes due to trends in the outflows are not part of the present study (for the discussion of the magnitude of that effect we refer to Latif et al. 2006).

The subgrid-scale mixing parameterizations used in the ORCA experiments include a representation of mixed layer dynamics by a turbulent kinetic energy (TKE) model, tracer advection is discretized by a monotonic upstream-centered scheme for conservational laws (MUSCL; Hourdin and Armengaud 1999).

Similar to FLAME the ORCA model is spun up from climatological initial conditions for $20 \mathrm{yr}^{3}$ After that a reference case (O_REF), and sensitivity experiments with interannual variability in specific forcing components only (O_WIND, O_HEAT, O_HEAT + SALT), have been performed. To account for spurious model drift unrelated to the external forcing in the assessment of the MOC variability in these experiments, the climatological spinup has been extended to year 66 (O_CLIM), resulting in a trend of about $-0.5 \mathrm{~Sv}$ decade $^{-1}$ for the midlatitude MOC; for the analysis of the forced MOC variability this trend has been subtracted in the analysis of the MOC time series of all model cases. A list of experiments is shown in Table 2.

\section{General aspects of MOC and heat transport}

The time-mean, zonally integrated volume transports of the reference experiments are depicted in Figs. 1a-c. The FLAME cases show similar MOC characteristics for both model resolutions (Figs. 1a,b), but with a lack of Antarctic Bottom Water in F_HIGH-RES. The major feature, which we will refer to in the reminder as the

\footnotetext{
${ }^{3}$ To assess the effect of the initialization shock after the spinup period we have performed two ensemble integrations: experiments that repeated the same forcing but each initialized by its predecessor. Analyzes of the variability shows that the main features of the MOC variability are very similar, demonstrating the overriding importance of the external forcing.
} 

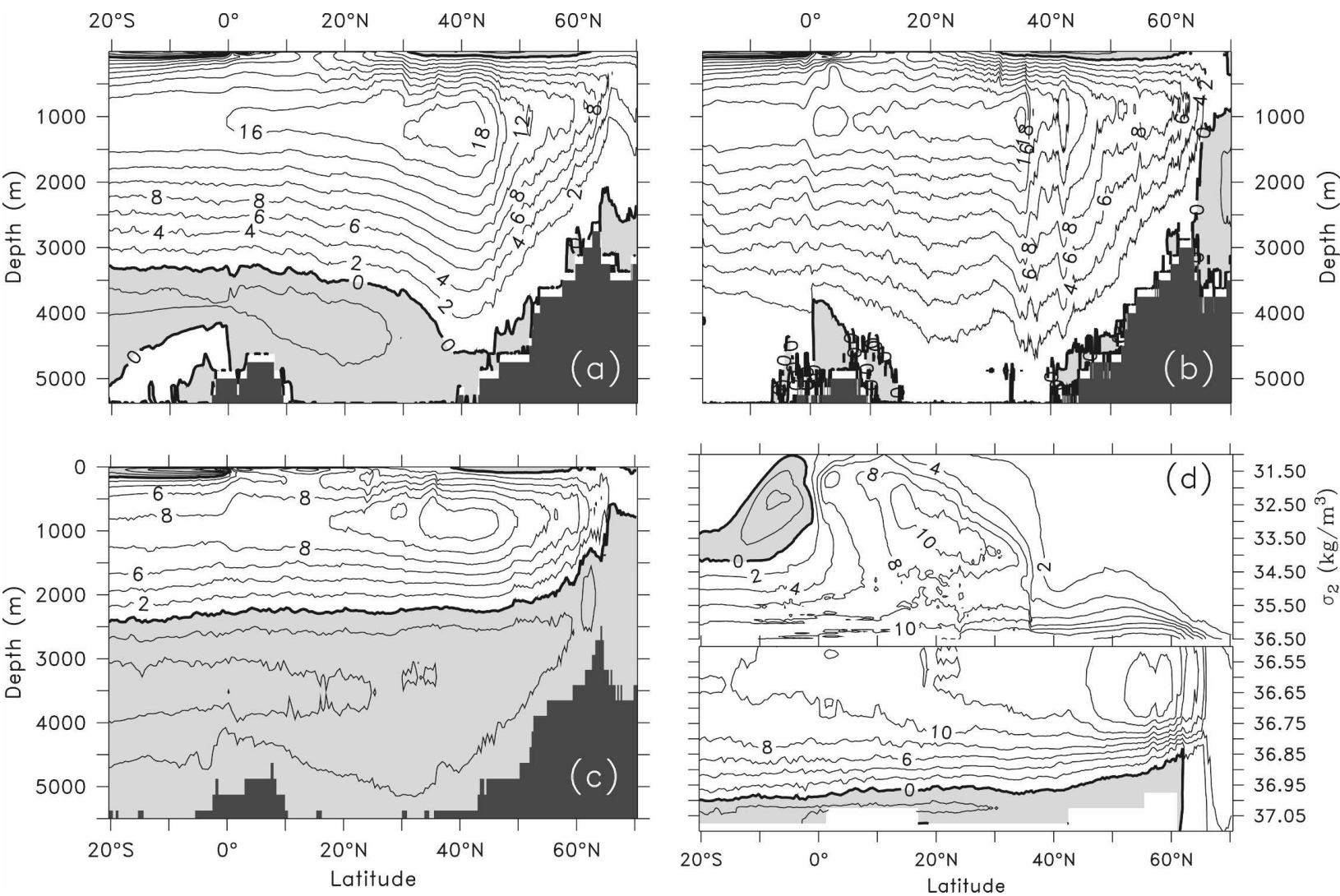

FIG. 1. Time-mean (1995-2000) meridional overturning as function of depth for experiments (a) F_REF, (b) F_HIGH-RES, (c) O_REF, and (d) as function of potential density $\left(\sigma_{2}\right)$ for ORCA (note the split of the $y$ axis for distinction into lighter and denser water masses). Contour interval is $2 \mathrm{~Sv}$ (light gray $\equiv$ negative values and dark gray $\equiv$ topography). The calculation of the overturning includes the eddy-induced velocity components (for F_REF and O_REF).

Atlantic MOC, is the deep North Atlantic Deep Water (NADW) cell, comprising northward flow above 1000 $\mathrm{m}$ and a sinking north of about $40^{\circ}-45^{\circ} \mathrm{N}$. Both FLAME cases exhibit maximum streamfunction values (referred to as the MOC maximum) here of about 18 Sv, in agreement with observational accounts (18.9 \pm 4 Sv; Talley 2003) and inverse studies (17 \pm 4 Sv; Ganachaud and Wunsch 2000). The model cases differ in the vertical extent of the cell, that is, in the depth of southward NADW transport, and the concomitant extent of the underlying cell related to the near-bottom transport of Antarctic Bottom Water (AABW) in the (sub-) tropics. Possible causes for the deepening are the representation of the dense overflow across the Greenland-Scotland Ridge (GSR) (e.g., Willebrand et al. 2001) but also resolution-dependent effects of the open southern boundary (e.g., Treguier et al. 2001) and the representation of Mediterranean outflow.

Compared to the FLAME experiments the ORCA run features a significantly shallower and weaker NADW cell: its maximum is only $12 \mathrm{~Sv}$, and with a depth extension to only $2000-2500 \mathrm{~m}$ it allows a much thicker AABW cell. Several factors appear instrumental: apart from some (rather slight) differences in the overflow properties due to the different northern damping configurations, a prime factor may be the BBL scheme, which, in the present ORCA configuration, appears much less effective compared to FLAME in limiting the spurious dilution of the dense outflow water during its downslope flow south of the sills.

Whereby the first factor seems to be of minor importance here (both FLAME cases and ORCA do feature bottom densities of $\sigma_{0}=27.9-28.0$ in the Denmark Strait), the lack of an inefficient BBL in ORCA may contribute to a loss of dense overflow components. In addition to these factors the FLAME cases have specified inflow conditions at their open southern boundaries, and are therefore more constrained to observations than ORCA.

Figure 1d shows the overturning in potential density coordinates (for a proper distinction between NADW and AABW $\sigma_{2}$ has been chosen) for the ORCA model. There is a strong difference in the NADW cell compared to the MOC in-depth coordinates in the subarctic 


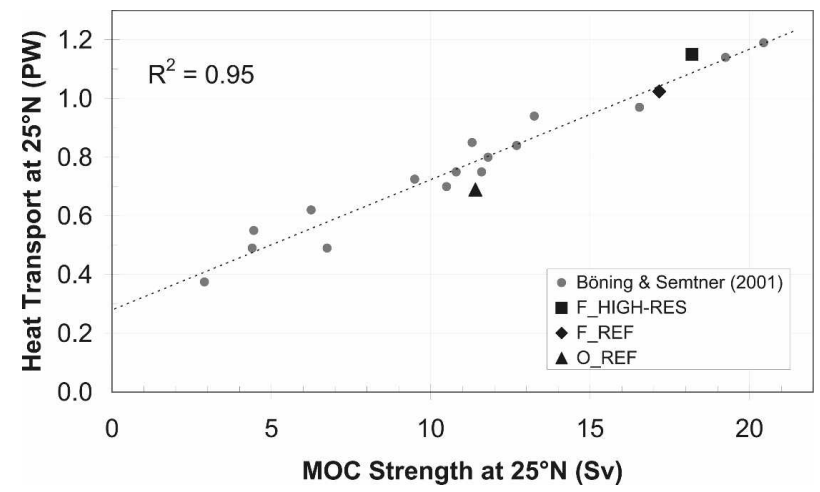

FIG. 2. Strength of the MOC (NADW cell) vs heat transport at $25^{\circ} \mathrm{N}$. Update of the compilation by Böning and Semtner (2001, BS), with gray dots representing values for a host of Atlantic models at different resolution $\left(1^{\circ}-1 / 6^{\circ}\right)$ and different architectures ( $z$, sigma, and isopycnal coordinates); black symbols are values for F_HIGH-RES, F_REF, and O_REF, averaged over the last 15-20 yr of model integration.

Atlantic, but similarity in the strength of the NADW cell strength south of about $40^{\circ} \mathrm{N}$. The analysis of the meridional transport variability in midlatitudes in the remaining sections will therefore be based on MOC in-depth coordinates.

It has been noted before that there is a close link between the strength of the NADW cell and the northward heat transport in the subtropical North Atlantic (e.g., Böning and Semtner 2001). The present FLAME and ORCA transports fit well into the previous range of model solutions, confirming the linear relation between these quantities (Fig. 2); note that this close relation even holds for O_REF, irrespective of its substantially lower MOC transport. Furthermore, it is interesting to assess the latitudinal range for which this relation holds: Fig. 3 shows the temporal correlation between the MOC and heat transports in the two reference experiments, both for monthly-mean time series (emphasizing the intraseasonal variability) and for their annually averaged portions. The integral transport quantities are well correlated for both spectral ranges across the subtropical-midlatitude North Atlantic. North of about $40^{\circ} \mathrm{N}$ this correlation, and thus the usefulness of the MOC in $z$ coordinates, breaks down because of the much higher importance for the northward heat transport of temperature contrasts in the zonal direction, that is, between the cold Labrador Current and the warm North Atlantic Current. Interestingly, there is still some correlation in subpolar latitudes in FLAME (although significant only on monthly scales), reflecting the impact of the deeper southward flow in this model; this is in contrast to ORCA where the signature of the dense overflows is effectively eroded away in the downslope flow regime.

In the following analysis of low-frequency transport variability we will focus on the latitudinal range of about $20^{\circ}$ to $40^{\circ} \mathrm{N}$ where the concept of the MOC indepth coordinates obviously does provide a useful means of assessing the large-scale meridional transport behaviors. A question of particular interest is whether the model-model differences, which reflect the range typically found in present ocean and climate models, and thus, of deficiencies in the representation of mean MOC features, have an impact on the low-frequency characteristics.

\section{Low-frequency variability characteristics}

The following analysis of the MOC variability is based on monthly time series of MOC strength; our focus is on time scales longer than the annual cycle.

For a first illustration of the temporal variability characteristics, time series of MOC strength are provided for the $1 / 3^{\circ}$ and $1 / 2^{\circ}$ FLAME reference cases in the subtropical North Atlantic; we specifically focus on a
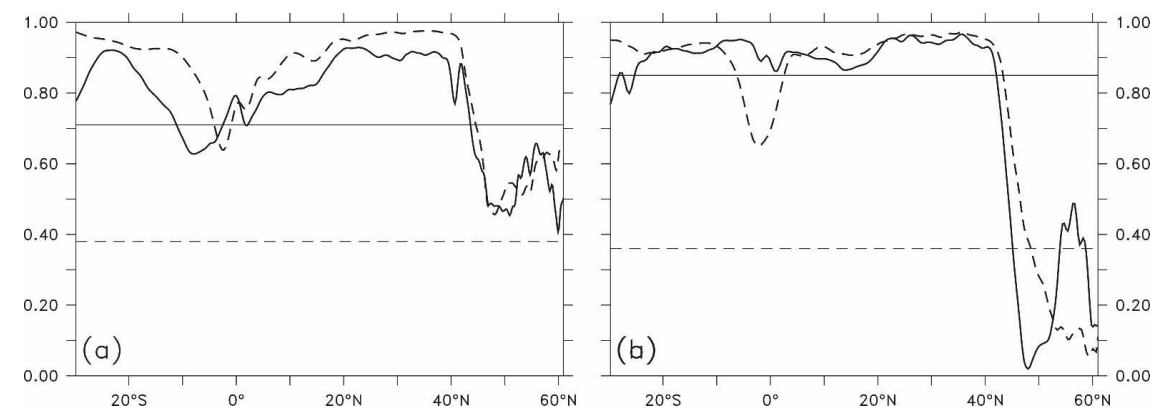

FIG. 3. Correlation of overturning strength (maximum of NADW cell) and heat transport variability on monthly (dashed) and interannual (solid) time scales for (a) FLAME and (b) ORCA. (Thin lines do indicate $95 \%$ significance levels after calculating the effective degrees of freedom, see, e.g., Emery and Thomson 1998.) 


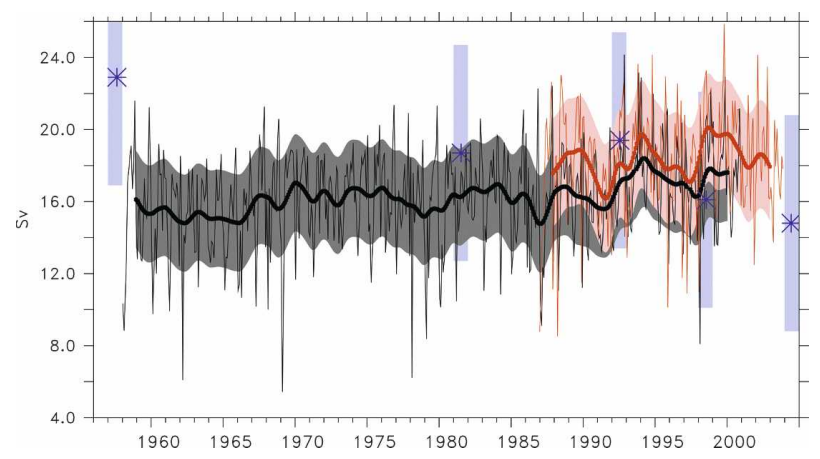

FIG. 4. Variability of the MOC strength at $26.5^{\circ} \mathrm{N}$ for experiments F_REF (black) and F_HIGH-RES (red). Shown are monthly values (thin lines) and the interannual variability, obtained by smoothing the time series by a 23 -month Hanning filter. The shading spans the range of one std dev of the monthly values to both sides of the low-pass-filtered curve. Marked by blue stars (shadings) are the observational estimates (error bars) of Bryden et al. (2005).

latitude circle $\left(26.5^{\circ} \mathrm{N}\right)$ close to the transoceanic section repeats analyzed by Bryden et al. (2005; Fig. 4). The MOC transport time series are dominated by highfrequency month-to-month and year-to-year variability, which appears much more vigorous than decadal signals or trends; because of these strong fluctuations, there appears no glaring inconsistency with the individual observational estimates (except, possibly, the 1957 value). Some first inferences about the nature of the variability can be drawn by comparing the different model cases. Interestingly, the stronger eddy intensity of the $1 / 2^{\circ}$ case (with a mean EKE along $26.5^{\circ} \mathrm{N}$ of the same magnitude as observed by Le Traon and Ogor (1998), and two orders of magnitude larger than in the $1 / 3^{\circ}$ case) has little effect on the standard deviation of the monthly values: in F_HIGH-RES $(2.7 \mathrm{~Sv})$ it is almost identical to F_REF (2.6 Sv). The variability in both cases is higher than in their climatological coun- terparts driven by a repeated annual cycle, that is, F_CLIM (1.8 Sv) and the climatological spinup of F_HIGH-RES (2.1 Sv; not shown), suggesting a contribution of less than a Sverdrup by the interannual forcing variability. While an exact separation between externally forced and internally induced contributions to the high-frequency part of the variability is not possible, an indication of the significance of the latter can also be seen in an almost lack of correlation between the monthly time series in F_REF and F_HIGH-RES ( $r=0.40$, with 0.30 being significant at the $95 \%$ significance level after calculating the effective degrees of freedom following Emery and Thomson 1998): the stochastic nature of the high-frequency part of the spectrum in these eddying solutions obviously masks possible, deterministic variability signals at longer periods. A more congruent model behavior emerges in the lowpass filtered time series: the model solutions are more similar here, with relative maxima in the late 1980s, mid-1990s, and late 1990s, although the $1 / 12^{\circ}$ record is somewhat short to formally assess the correlation $(r=$ 0.74 , with 0.78 being significant).

We will focus now on the low-frequency part of the MOC variability, first by inspecting the low-pass filtered time series of the $1 / 3^{\circ}$ FLAME and the $1 / 2^{\circ}$ ORCA reference experiments; time series are presented now for $36^{\circ} \mathrm{N}$ since this is closer to the total strength of the NADW cell and signals do appear clearer (Fig. 5). In marked contrast to their difference in the mean transports, both models exhibit similar variability characteristics: a year-to-year variability of, typically, $O(2 \mathrm{~Sv})$, but up to twice that value in individual years, and extrema occurring at the same times. Both models show an interdecadal modulation of the interannual signal: in the 10-yr filtered time series we note a general increase toward higher MOC values in the 1990s. The variability in the interannual-decadal range of both models is in
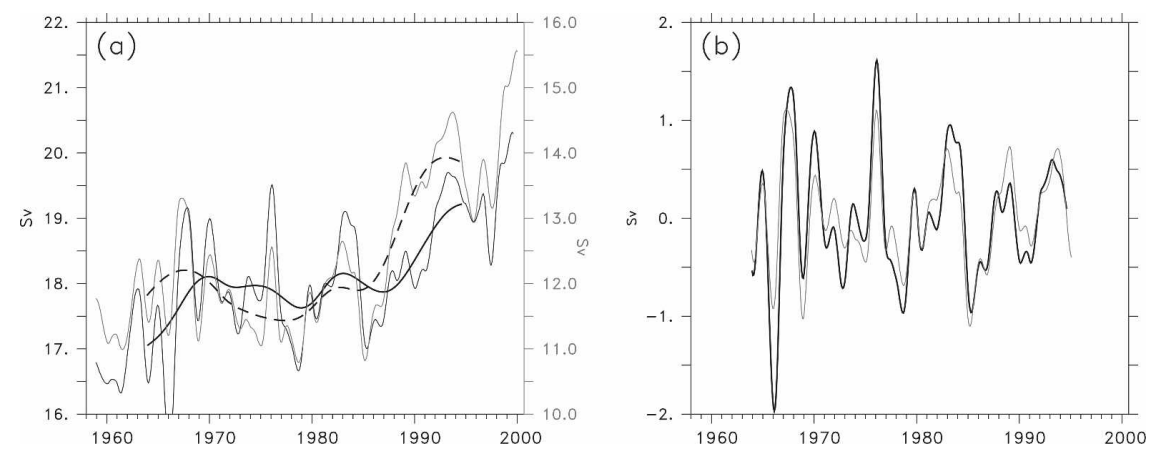

FIG. 5. Time series of MOC strength at $36^{\circ} \mathrm{N}$ in FLAME (black) and ORCA (gray or dashed) reference experiments (to avoid the spurious model trend in ORCA expt O CLIM has been subtracted): (a) 2-yr (thin) and 10-yr (thick) low-pass filtered, (b) 2-10-yr bandpass filtered. 

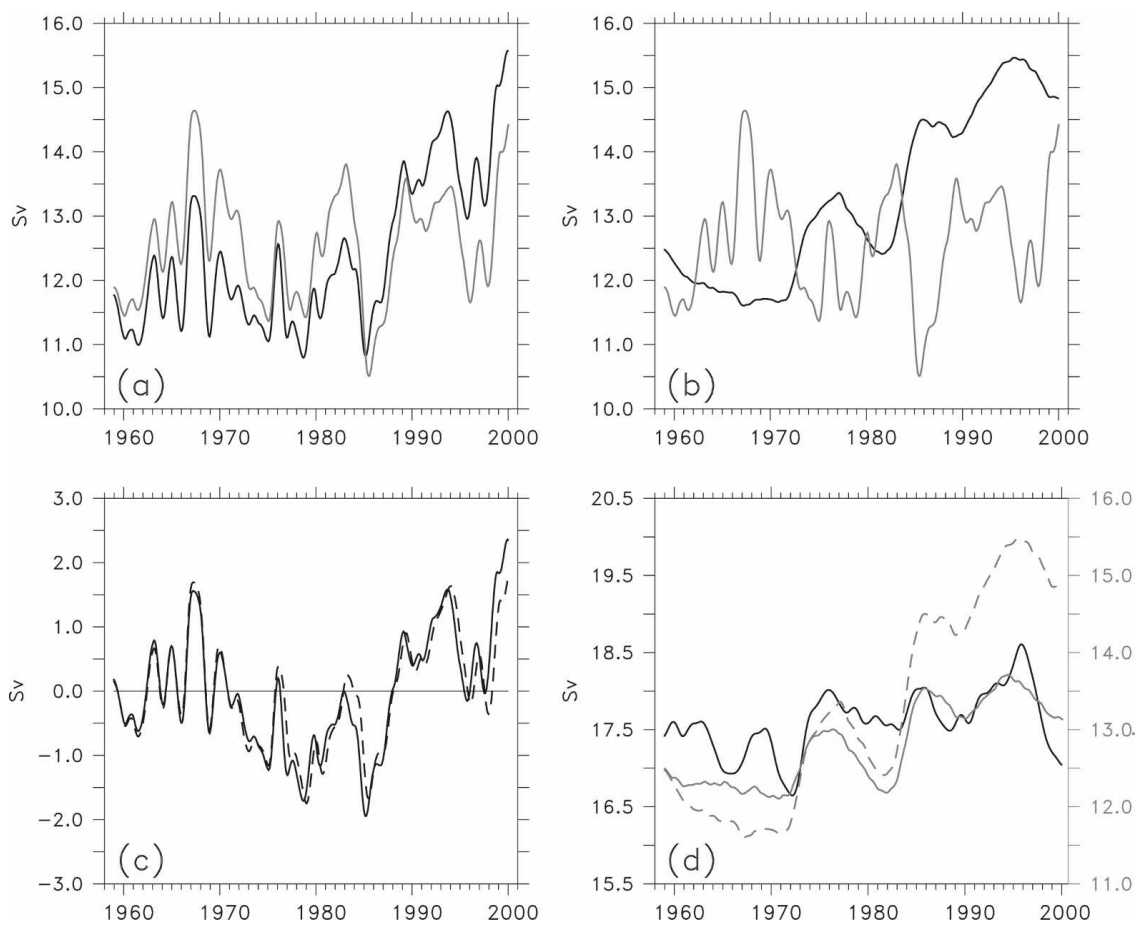

FIG. 6. Contribution of different forcing components to MOC, as simulated in ORCA experiments: (a) O_REF (black) and O_WIND (gray), (b) O_WIND (gray) and O_HEAT + SALT (black), (c) anomalies of O_REF (black) and sum of O_WIND and O_HEAT + SALT (dashed). (d) As in Fig. 5a, but for sensitivity experiments forced with climatological wind stress: F_HEAT (black), O_HEAT (gray solid), and O_HEAT + SALT (gray dashed). (For all ORCA time series the trend of O_CLIM has been subtracted.)

striking correspondence (Fig. 5b) if the time series is bandpass filtered for the $2-10 \mathrm{yr}$ range: as noticed in a previous model-model comparison by Beismann et al. (2002), the MOC variabilities appear similar in the two solutions. The robustness across models differing in domain size and various choices of numerics and parameterizations obviously points to the importance of the atmospheric forcing as the governing factor for the MOC variability in this spectral range; more specifically, since both configurations differ in the simulation of exchanges with the Arctic Ocean and South Atlantic, and also in the specification of surface freshwater forcing, the key factors governing the MOC can only be the heat flux forcing and the wind stress, which in both models are build on the NCEP reanalysis; effects due to the modifications in the CORE forcing or due to the different formulations of the heat flux appear of secondary importance.

\section{Causes of MOC variability}

What is the role of different forcing components in the generation of midlatitude MOC variability? We start to address this question by examining the ORCA sensitivity experiments in which the atmospheric forcing applied to the reference case (O_REF) was perturbed by artificially restricting its interannual variability to either only the wind stress (WIND), the heat flux (O_HEAT), and the heat and freshwater fluxes (O_HEAT + SALT) ${ }^{4}$ Figure 6a compares the MOC transport variability in O_REF (black curve) and WIND (gray). It is evident that the variability in the wind-driven circulation, that is, the effect of the wind stress alone, accounts for a large fraction of the lowfrequency signal. The effect of the wind stress is not confined to interannual time scales but is also responsible for longer-term changes. Figure $6 \mathrm{~b}$ introduces the opposite case: climatological wind stress, but interannual thermohaline forcing for the heat and freshwater components (O_HEAT + SALT, black curve). In this case the MOC exhibits a completely different characteristic: the variability is more confined to decadal and

\footnotetext{
${ }^{4}$ Note the artificial nature of these forcing configurations: it implies that wind variability is accounted for differently in the surface momentum, heat, and freshwater fluxes.
} 
longer time scales and weaker in amplitude, $O(1 \mathrm{~Sv})$, with an increasing trend of $O(2-3 \mathrm{~Sv})$ from about 1970 to the 1990 s.

Given that a separation of the long-term mean MOC into a "wind driven" and a "thermohaline" part is not possible because of the inherently nonlinear nature of the ocean circulation, for example, because of the advection of heat and salt, an important question arising here is whether such a separation is possible in a meaningful way for the midlatitude MOC variability. More specifically, can the MOC anomalies, that is, the transport deviations from the long-term mean, of the reference experiment be regarded as the sum of the anomalies forced by the wind stress and thermohaline fluxes individually? This question is addressed in Fig. 6c: it is remarkable to find the MOC anomaly time series of the reference case almost exactly replicated by a linear superposition of the individually forced runs.

Whereas the causes of midlatitude MOC variability can thus, to lowest order (and for a noneddying solution), be rationalized in terms of wind-driven circulation changes superimposed on a buoyancy-forced signal, a further dissection of the latter becomes problematic. As discussed below, the bulk of that signal is related to the variability in the deep-water formation in the subpolar North Atlantic. It is well established from previous studies that this variability is mainly tied to changes in the local heat flux associated with the largescale atmospheric conditions (e.g., Eden and Willebrand 2001); however, an identification of the relative impact of the freshwater flux is not straightforward, since it may involve nonlocal processes such as changes of freshwater export from the Arctic, which, in turn, are associated with wind-driven changes in the subarctic circulation (Gerdes et al. 2005). While a rigorous analysis of the individual role of that effect is beyond the scope of the present study an impact on the amplitude of the MOC variability is to be noted; in particular, the prominent upward trend in O_HEAT + SALT becomes considerably weaker in O_HEAT, and more similar to the trend simulated in F_HEAT.

Previous model studies have shown a close link of the "thermohaline" part of the MOC variability with the buoyancy forcing over the western subpolar gyre, and thus, with the variability in the convection intensity in the Labrador Sea (Eden and Willebrand 2001; Getzlaff et al. 2005; Böning et al. 2006). The present model sequence allows to test this link by comparing the behavior of solutions varying in details of deep winter convection: whereas the FLAME models maximum depths are confined to the western part of the Labrador Sea, in good correspondence to observations (Lab Sea Group 1998), the non-eddy-permitting ORCA produces deep convection over a much broader area of the Labrador Sea. The important point relevant for this study is that the differences between the convection characteristics in the FLAME and ORCA reference cases can be taken as an expression of existing model deficits in general, and thus offer a valuable means for examining the robustness of model simulations concerning the MOC response to subarctic forcing variability.

As discussed in Brandt et al. (2007) and Haine et al. (2008), there are several possibilities for defining a quantitative measure of convection intensity. Since our interest here is not on the intricate details of LSW formation variability itself, but on elucidating its effect on the MOC, we have used the rather simple diagnostic described by Böning et al. (1996), which basically follows the classical account of LSW formation by Clarke and Gascard (1983): the formation rate is defined as the increase in volume during the winter convection phase between December and April, of the water in the density range of the model equivalent of LSW (27.84-27.89 in FLAME; 27.72-27.82 in ORCA); dividing this volume of "new" LSW by a year, gives the annual formation rate (Sv). The time series of LSW formation are depicted in Fig. 7a for FLAME and Fig. 8a for ORCA, showing broad similarities in basic characteristics: values vary between minima of nearly zero and maxima of 7-8 Sv, a period of very weak LSW formation around 1970 is followed by a series of major convection periods during the mid-1970s, mid-1990s, and the first half of the 1990s. The similarity in these gross features reflects the dominant role of the large-scale atmospheric forcing, specifically of the winter heat loss over the subpolar North Atlantic.

The repercussions of the subarctic variability for the MOC can be assessed in the model cases where effects of wind-driven variability are artificially excluded; that is, F_HEAT (Fig. 7b) and O_HEAT + SALT (Fig. 8b). In both models, the onset of intensified LSW production around 1972-73, 1982-83, and 1989 is followed by positive MOC anomalies at the southern edge of the subpolar gyre (near $45^{\circ} \mathrm{N}$ ) with a delay of about 1-2 yr. Both models also show an increasing trend in the amplitude of the transport anomalies; however, since there is no strong difference between the amplitude of LSW formation rates in the 1970s and 1990s, this trend cannot simply be explained in terms of the LSW formation intensity, but rather appears related to the increasing frequency of intense convection years from the 1970s to the 1990s. While the amplitude of the MOC response in ORCA is about twice as high as in FLAME, both models show a fast southward communication of the MOC variability through the midlatitude North Atlantic; in 

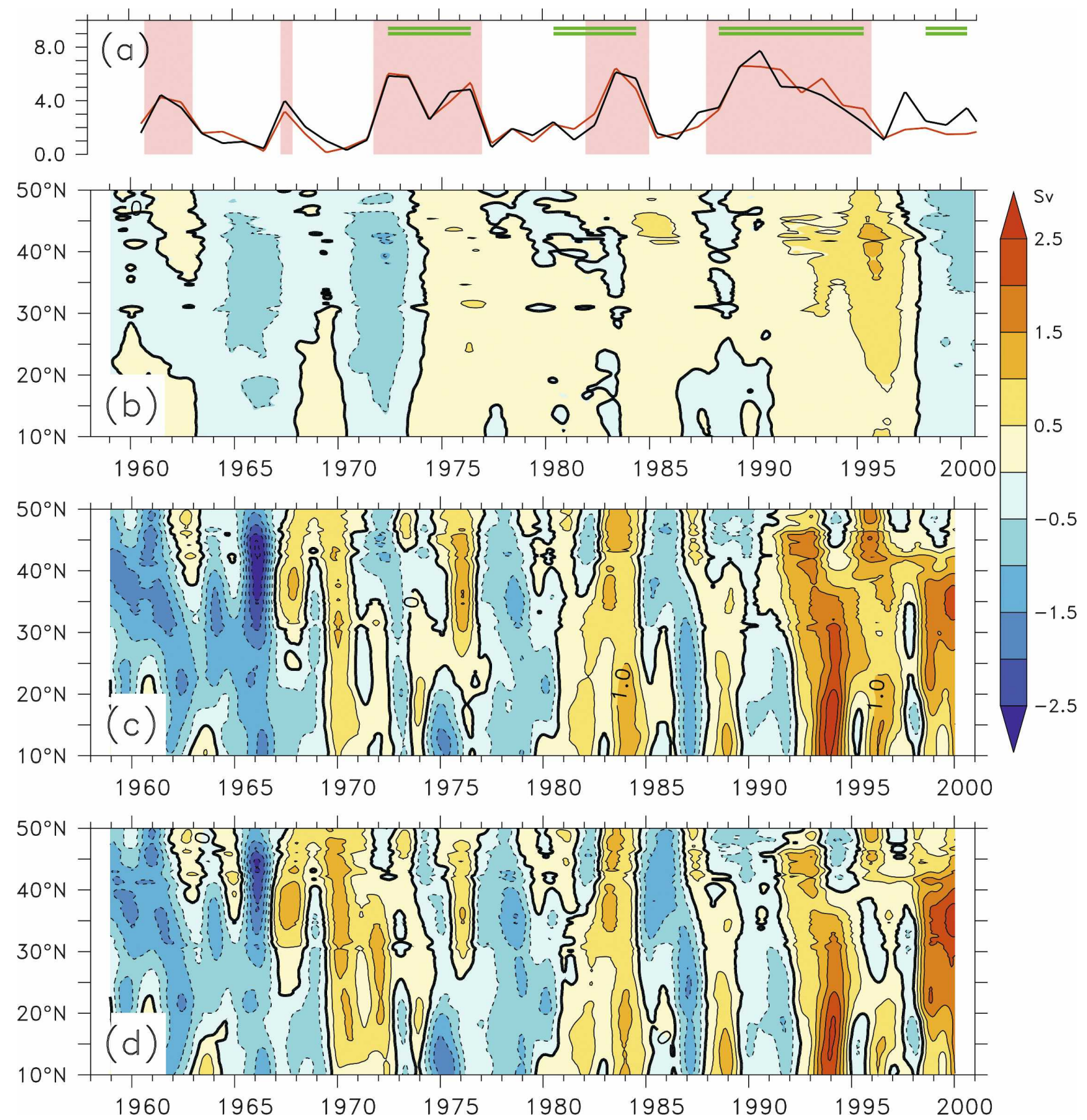

FIG. 7. (a) LSW formation rate [defined by the increase of LSW volume during wintertime convection (Sv)] for F_REF (black) and F_HEAT (red, shaded are values above $2.5 \mathrm{~Sv}$, indicated by green lines are phases of positive NAO); and Hovmöller diagrams depicting the meridional propagation of MOC anomalies (defined by the streamfunction at 1000-m depth) for (b) F_HEAT, (c) F_REF, and (d) a virtual experiment "F_WIND" (= F_REF-F_HEAT).

both cases the transport signal is attenuated by a factor of about 3 between subpolar $\left(40^{\circ}-45^{\circ} \mathrm{N}\right)$ and subtropical $\left(26.5^{\circ} \mathrm{N}\right)$ latitudes (cf. Getzlaff et al. 2005 , who have examined the propagation of that signal, but mainly for a $4 / 3^{\circ}$-resolution case in FLAME).

By superimposing the effect of wind-driven circulation variability (in F_REF and O_REF), the clear re- lation to the convection variability disappears (Figs. 7c and $8 \mathrm{c}$ ). The prominent decadal signal governing the buoyancy-forced MOC anomalies is now masked by the stronger, higher-frequency signal. Accordingly, the meridional-coherent structure of the former is replaced by wind-driven anomalies with maximum amplitudes at varying latitudes, sometimes of a more local character, 

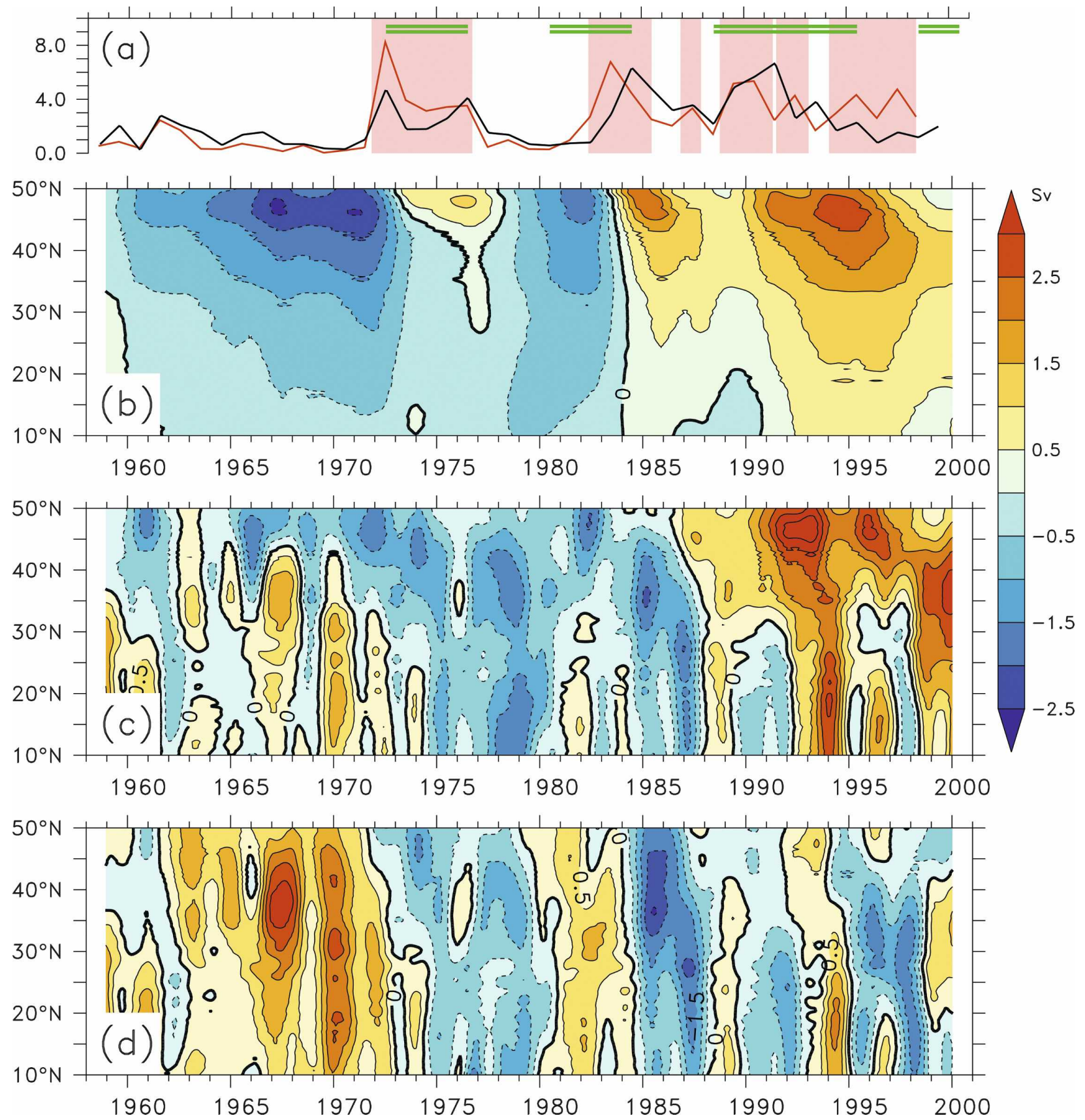

FIG. 8. Similar to Fig. 7 but for (a) O_REF (black) and O_HEAT + SALT (red), (b) O_HEAT + SALT, (c) O_REF, and (d) O_WIND.

sometimes spanning a larger latitudinal extent. It has been noted above that the total MOC variability (in O_REF) can to a high degree be explained by linearly superimposing the individual, buoyancy- and windforced solutions (the demonstration shown before for $36^{\circ} \mathrm{N}$ holds throughout the midlatitudes). To assess the wind-driven signatures in isolation, a "virtual" FLAME "WIND" case was thus calculated by taking the differ- ence of F_REF minus F_HEAT; the MOC of that case (Fig. 7d) can directly be compared with ORCA WIND (Fig. 8d): while there is a similarity in the gross patterns of the anomalies, there are differences in detail (correlations are $0.5-0.7$ in the midlatitudes) despite the (nearly) identical wind forcing.

There is a marked difference in the meridionalcoherence scales of MOC anomalies related to thermo- 

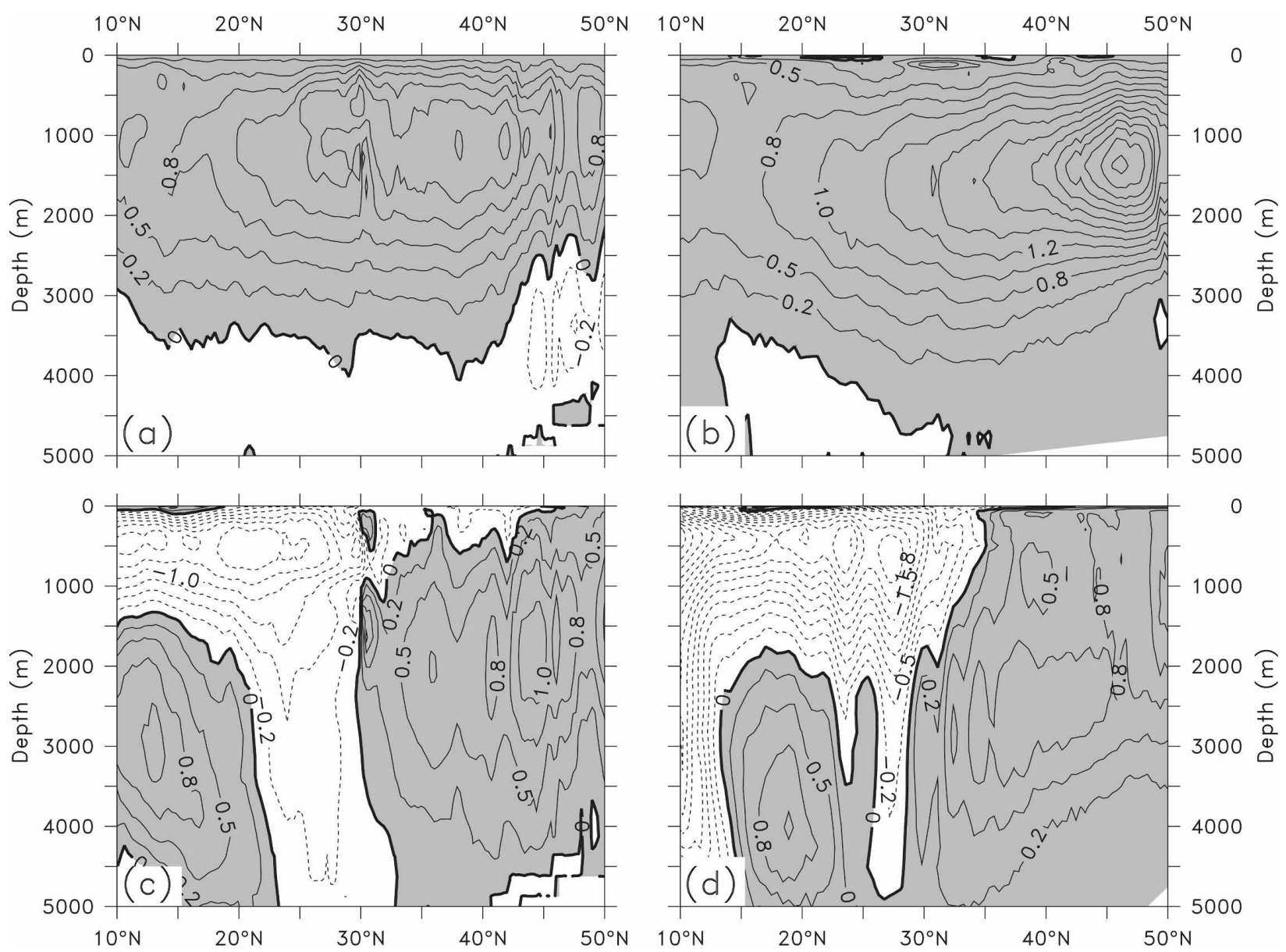

FIG. 9. Spatial structure of thermohaline vs wind-driven MOC changes, illustrated by the 1976-72 streamfunction differences (Sv) for (a) F_HEAT, (b) O_HEAT + SALT, (c) "F_WIND," and (d) O_WIND.

haline and wind forcing, as revealed (Fig. 9) by the difference pattern between the annual mean transports of years with high MOC transport (1976) and a low transport (1972). The buoyancy-forced MOC changes (Figs. 9a,b) exhibit a similar, basin-scale pattern in the two models, reflecting the spinning up of the NADW cell in response to changes in LSW formation, associated with the rapid equatorward communication of the subpolar signal. The wind-driven variability is of a rather different structure, characterized by meridional more confined patterns with more complex, deepreaching features, with notable deviations between the different models.

A summary view of the relative importance of MOC variations induced by buoyancy forcing, wind forcing, and internal processes (i.e., eddy variability) is provided in Fig. 10, by depicting the standard deviation of the MOC in the different FLAME and ORCA cases as a function of latitude. We first note that MOC anomalies caused by thermohaline forcing variability, that is, the signal related to deep-water formation variability in the subpolar North Atlantic, provides only a small contribution to the total MOC variability, especially in the subtropical-tropical Atlantic (Fig. 10a). The net MOC variability is primarily governed by wind stress-induced and internally induced anomalies, with the wind-driven signal dominating in the subtropics, and eddy effects dominating north of about $30^{\circ} \mathrm{N}$, with a peak in the latitude range of the Gulf Stream around $36^{\circ}-38^{\circ} \mathrm{N}$. The wind stress and buoyancy-forced signals are delineated in Fig. 10b by contrasting the FLAME and ORCA solutions. First to note here is the similarity in the latitudinal distributions: the amplitude of the buoyancy-forced signal is strongest at the southern exit of the subpolar basin at about $45^{\circ} \mathrm{N}$ and gradually fades toward the equator. Whereas the wind-driven MOC variance is rather similar in the ORCA and FLAME solutions, the heat flux related signal in the ORCA solution is significantly higher in the subtropical North Atlantic than in FLAME, possibly related to the fact 

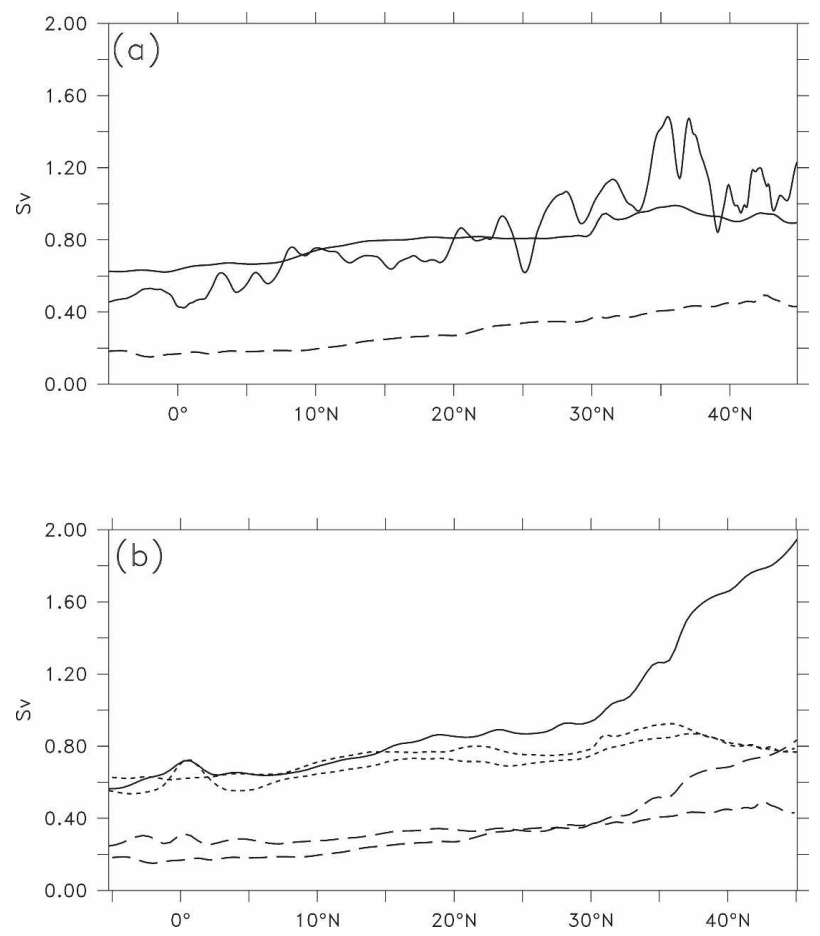

FIG. 10. (a) Std dev of the interannual MOC variability in (a) F_HIGH-RES (gray), F_REF (black solid), and F_HEAT (black dashed). (b) Comparison between FLAME (black) and ORCA (gray). Shown are the HEAT (dashed), HEAT + SALT (solid), and (virtual) WIND (dotted) experiments.

that the latter thermal forcing involves a damping toward climatological SST values; the presence of interannually varying freshwater forcing in ORCA further increases the variability. In summary, the latter solution (i.e., O_HEAT + SALT) is taken as a "best guess" for the amplitude of a MOC signal of thermohaline, subarctic origin in the present sequence of experiments (since it includes a complete freshwater forcing and has less stringent surface damping), that signal is superimposed in the subtropical North Atlantic $\left(26.5^{\circ} \mathrm{N}\right)$ by a wind-driven year-to-year variability with a more than 2 times higher standard deviation.

\section{Summary and discussion}

A suite of numerical experiments based on two different model configurations has been used to examine the causes governing interannual-decadal MOC variability in the North Atlantic. In spite of substantial differences in the strength and pattern of the mean MOC in ORCA and FLAME, the MOC variability exhibited similar characteristics. First to note is the close correspondence between MOC and heat transport variability for the subtropical-midlatitude North Atlantic: on both intraseasonal and interannual time scales the correlation exceeds 0.9 between $10^{\circ}$ and $40^{\circ} \mathrm{N}$, while it fades in the subpolar regime, north of $40^{\circ}-45^{\circ} \mathrm{N}$ and to a lesser degree in the tropical Atlantic. The behavior reflects the unique spatial structure of large-scale meridional transport in the subtropical North Atlantic where the zonal temperature gradients are relatively weak and southward transport of cold water occurs well below the northward transport of warm, rendering the MOC (in depth coordinates) a useful diagnostic in this regime.

A second important feature of the reference solutions is the striking similarity of the MOC variability in FLAME and ORCA for interannual-decadal time scales (2-10 yr). A robustness across different model systems, if forced by similar atmospheric conditions, was already noted by Beismann et al. (2002). A similarity in variability characteristics was also found by Beismann and Barnier (2004) in a series of eddypermitting models differing in mean overflow and mean MOC strengths. The robustness in model solutions clearly suggests a predominantly linear nature of the MOC's response to atmospheric forcing variability on these time scales.

Our analysis of the role of buoyancy (primarily, heat flux) and wind stress-related forcing mechanisms was based on sequences of model experiments with artificial perturbations in the surface fluxes, that is, by considering the individual effects of either wind stress $\left(\mathrm{O}_{-}\right.$ WIND), heat flux (O_HEAT), or heat and freshwater flux (O_HEAT + SALT) in isolation. A remarkable result of the (ORCA) solutions is that the sum of the MOC anomalies of the O_WIND and O_HEAT + SALT cases very closely reproduces the anomalies of the reference simulation. It is not clear to what extent this linear behavior would carry over to a highresolution eddying case; we note, however, that the net contribution of internally induced fluctuations in the subtropical North Atlantic appears smaller than winddriven changes. For the analysis of weakly or noneddying cases such as the FLAME $\left(13^{\circ}\right)$ and ORCA $\left(12^{\circ}\right)$ models examined here, it implies that the MOC variability of the reference, hindcasting simulations can meaningfully be separated into contributions of thermohaline and wind-forced origin.

Aspects of the thermohaline MOC signal in isolation were studied already in Getzlaff et al. (2005) and Böning et al. (2006), characterized by a decadal-scale variability of $O(1-2 \mathrm{~Sv})$ at about $40^{\circ} \mathrm{N}$, rapidly spreading to the tropical Atlantic while decreasing in strength; the amplitude at $26.5^{\circ} \mathrm{N}$ is only about $1 \mathrm{~Sv}$. The present analysis confirms the link of this signal to the variability of deep-water formation in the Labrador Sea in both 
FLAME and ORCA, despite the model-model differences in the simulation of convection patterns. Previous model studies have shown that the intensity of deep winter convection and the formation rate of LSW are governed by the local heat fluxes, and thus the atmospheric conditions as described by the NAO (Häkkinen 1999; Eden and Willebrand 2001); accordingly, the main variability features in the two models are basically similar, with positive MOC anomalies following about 2-3 yr after the onset of intensified LSW production phases, and a general intensification from the 1970s to maximum values attained in the mid-1990s.

The interdecadal MOC trend has to be regarded with some caution, however, since both models lack in capturing possible low-frequency variations in the Nordic seas water mass transformations. While the ORCA cases, in principle, include an explicit simulation of exchanges with the Nordic seas, potential trends in the water masses are effectively damped in the present configuration, so that possible effects, for example, of changes in the overflow conditions, are excluded from the present considerations. The role of such changes has been examined in recent complementary model studies: Using a sequence of response experiments with atmospheric forcing tendencies from IPCC climate scenario runs, Schweckendiek and Willebrand (2005) demonstrated that long-term trends in the MOC could primarily be linked to changes in the Nordic water masses, whereas decadal MOC variability appeared to be mainly caused by atmospheric forcing over the North Atlantic proper. The magnitude of the MOC response to changes in the density of the overflow water was examined in a host of response experiments by Latif et al. (2006); the results suggested that the observed freshening (e.g., Dickson et al. 2002) of Denmark Straits overflow during the last decades might have caused a gradual weakening of the midlatitude MOC of about $1 \mathrm{~Sv}$.

A conspicuous feature of both the ORCA and FLAME series is the dominance of high-frequency fluctuations in the midlatitude MOC due to local wind forcing and (in the high-resolution case) eddy variability, effectively masking the decadal-scale and longer-term changes associated with subarctic deep-water formation. In the high-resolution case the standard deviation of the monthly MOC time series ( $3 \mathrm{~Sv}$ ) is significantly larger than the thermohaline, LSW-related changes in FLAME and ORCA (1.7 and 1.8 Sv). The intraseasonal variability signal is even more prominent in daily MOC time series, exhibiting a pronounced response, of $O(20$ $\mathrm{Sv})$, to the synoptic variability in the atmospheric forcing (cf. Böning et al. 2001); the magnitude of this variability is similar to the observational findings of Cun- ningham et al. (2007) from a year-long time series of the RAPID array. An interesting aspect of the model solutions in this regard is the rather close correspondence between the wind-driven MOC fluctuations in (noneddy-resolving) FLAME and ORCA. This model robustness suggests that, given a sufficiently accurate knowledge of the wind stress, this deterministic part of an observed MOC time series might in principle be estimated. Another aspect of potential relevance for the detectability of decadal-scale thermohaline changes of $O(1 \mathrm{~Sv})$ in noisy midlatitude MOC records is the much larger meridional coherence of this signal compared to the higher-frequency wind and eddy-related fluctuations, including its close link to changes in deepwater formation in the subpolar North Atlantic.

Acknowledgments. The integration of the experiments has been performed at Höchstleistungsrechenzentrum Stuttgart (HLRS) and the Deutsches Klimarechenzentrum Hamburg (DKRZ). We gratefully thank the NEMO System Team and the FLAME Group for the technical support during all stages of the model setup and integration. The study was supported by the Bundesministerium für Bildung und Forschung, project Nordatlantik (03F0443B AP 3.2).

\section{REFERENCES}

Arakawa, A., and V. R. Lamb, 1981: A potential enstrophy and energy conserving scheme for the shallow water equations. Mon. Wea. Rev., 109, 18-36.

Baehr, J., J. Hirschi, J.-O. Beismann, and J. Marotzke, 2004: Monitoring the meridional overturning circulation in the North Atlantic: A model-based array design study. J. Mar. Res., 62, 283-312.

Bailey, D. A., P. B. Rhines, and S. Häkkinen, 2005: Formation and pathways of North Atlantic Deep Water in a coupled ice ocean model of the Arctic North Atlantic Oceans. Climate Dyn., 25, 497-516.

Barnier, B., L. Siefridt, and P. Marchesiello, 1995: Thermal forcing for a global ocean circulation model from a three-year climatology of ECMWF analyses. J. Mar. Syst., 6, 363-380.

_ , and Coauthors, 2006: Impact of partial steps and momentum advection schemes in a global ocean circulation model at eddy permitting resolution. Ocean Dyn., 56, 543-567.

Beckmann, A., and R. Döscher, 1997: A method for improved representation of dense water spreading over topography in geopotential-coordinate models. J. Phys. Oceanogr., 27, $581-$ 591.

Beismann, J.-O., and R. Redler, 2003: Model simulations of CFC uptake in the North Atlantic Deep Water: Effects of parameterizations and grid resolution. J. Geophys. Res., 108, 3159, doi:10.1029/2001JC001253.

_ turning circulation of the North Atlantic: Sensitivity to overflows of dense water masses. Ocean Dyn., 54, 537, doi:10.1007/s10236-004-0100-0.

— C. W. Böning, and D. Stammer, 2002: Inter-annual to de- 
cadal variability of the meridional overturning circulation of the Atlantic: A comparison of the response to atmospheric fluctuations in three ocean models. CLIVAR Exchanges, No. 3/4, International CLIVAR Project Office, Southampton, United Kingdom, 34-46.

Bentsen, M., H. Drange, T. Furevik, and T. Zhou, 2004: Simulated variability of the Atlantic meridional overturning circulation. Climate Dyn., 22, 701-720.

Biastoch, A., and W. Krauss, 1999: The role of mesoscale eddies in the source regions of the Agulhas Current. J. Phys. Oceanogr., 29, 2303-2317.

Böning, C. W., and P. Herrmann, 1994: Annual cycle of poleward heat transport in the ocean: Results from high-resolution modeling of the North and equatorial Atlantic. J. Phys. Oceanogr., 24, 91-107.

— , and A. Semtner, 2001: High-resolution modelling of the thermohaline and wind-driven circulation. Ocean Circulation and Climate, G. Siedler et al., Eds., Academic Press, 59-77.

— , F. O. Bryan, W. R. Holland, and R. Döscher, 1996: Deepwater formation and meridional overturning in a highresolution model of North Atlantic. J. Phys. Oceanogr., 26, 1142-1164.

— C. Dieterich, B. Barnier, and Y. Jia, 2001: Seasonal cycle of meridional heat transport in the subtropical North Atlantic: A model intercomparison in relation to observations near $25^{\circ}$ N. Prog. Oceanogr., 48, 231-253.

— M. Rhein, J. Dengg, and C. Dorow, 2003: Modeling CFC inventories and formation rates of Labrador Sea Water. Geophys. Res. Lett., 30, 1050, doi:10.1029/2002GL014855.

— M. Scheinert, J. Dengg, A. Biastoch, and A. Funk, 2006: Decadal variability of subpolar gyre transport and its reverberation in the North Atlantic overturning. Geophys. Res. Lett., 33, L21S01, doi:10.1029/2006GL026906.

Brandt, P., F. A. Schott, A. Funk, and C. S. Martins, 2004: Seasonal to interannual variability of the eddy field in the Labrador Sea from satellite altimetry. J. Geophys. Res., 109, C02028, doi:10.1029/2002JC001551.

— A. Funk, L. Czeschel, C. Eden, and C. Böning, 2007: Ventilation and transformation of Labrador Sea Water and its rapid export in the deep Labrador Current. J. Phys. Oceanogr., 37, 946-961.

Brauch, J. P., and R. Gerdes, 2005: Response of the northern North Atlantic and Arctic oceans to a sudden change of the North Atlantic Oscillation. J. Geophys. Res., 110, C11018, doi:10.1029/2004JC002436.

Bryan, K., 1982: Seasonal variation in meridional overturning and poleward heat transport in the Atantic and Pacific oceans: A model study. J. Mar. Res., 40, 39-53.

Bryden, H., H. R. Longworth, and S. A. Cunningham, 2005: Slowing of the Atlantic meridional overturning circulation at $25^{\circ}$ N. Nature, 438, 655-657.

Chanut, J., B. Barnier, L. Debreu, W. Large, L. Debreu, T. Penduff, J.-M. Molines, and P. Mathiot, 2008: Mesoscale eddies in the Labrador Sea and their contribution to convection and restratification. J. Phys. Oceanogr., 38, 1617-1643.

Clarke, R. A., and J.-C. Gascard, 1983: The formation of Labrador Sea Water. Part I: Large-scale processes. J. Phys. Oceanogr., 13, 1764-1778.

Cunningham, S., and Coauthors, 2007: Temporal variability of the Atlantic meridional overturning circulation at $26.5^{\circ} \mathrm{N}$. Science, 317, 935-938.

Curry, R. G., M. S. McCartney, and T. M. Joyce, 1998: Oceanic transport of subpolar climate signals to mid-depth subtropical waters. Nature, 391, 575-577.

Dickson, B., I. Yashayaev, J. Meincke, B. Turrell, S. Dye, and J. Holfort, 2002: Rapid freshening of the deep North Atlantic Ocean over the past four decades. Nature, 416, 832-837.

Döscher, R., and R. Redler, 1997: The relative influence of North Atlantic overflow and subpolar deep convection on the thermohaline circulation in an OGCM. J. Phys. Oceanogr., 27, 1894-1902.

DRAKKAR Group, 2007: Eddy-permitting ocean circulation windcasts of past decades. CLIVAR Exchanges, No. 12, International CLIVAR Project Office, Southampton, United Kingdom, 8-10.

Eden, C., and J. Willebrand, 2001: Mechanism of interannual to decadal variability of the North Atlantic circulation. J. Climate, 14, 2266-2280.

, and C. W. Böning, 2002: Sources of eddy kinetic energy in the Labrador Sea. J. Phys. Oceanogr., 32, 3346-3363.

— the North Atlantic climate system. J. Climate, 16, 4043-4060.

Emery, W. J., and R. E. Thomson, 1998: Data Analysis Methods in Physical Oceanography. Pergamon, 634 pp.

Fichefet, T., and M. A. Morales Maqueda, 1999: Modelling the influence of snow accumulation and snow-ice formation on the seasonal cycle of the Antarctic sea-ice cover. Climate Dyn., 15, 251-268.

Ganachaud, A., and C. Wunsch, 2000: Improved estimates of global ocean circulation, heat transport and mixing from hydrographic data. Nature, 408, 453-457.

Gent, P. R., and J. McWilliams, 1990: Isopycnal mixing in ocean circulation models. J. Phys. Oceanogr., 20, 150-155.

Gerdes, G., J. Hurka, M. Karcher, F. Kauker, and C. Köberle, 2005: Simulated history of convection in the Greenland and Labrador seas, 1948-2001. The Nordic Seas: An Integrated Perspective, Geophys. Monogr., Vol. 158, Amer. Geophys. Union, 221-238.

Getzlaff, J., C. W. Böning, C. Eden, and A. Biastoch, 2005: Signal propagation in the North Atlantic overturning. Geophys. Res. Lett., 32, L09602, doi:10.1029/2004GL021002.

Girton, J. B., and T. B. Sanford, 2003: Descent and modification of the overflow plume in the Denmark Strait. J. Phys. Oceanogr., 33, 1351-1364.

Gregory, J. M., and Coauthors, 2005: A model intercomparison of changes in the Atlantic thermohaline circulation in response to increasing atmospheric $\mathrm{CO}_{2}$ concentration. Geophys. Res. Lett., 32, L12703, doi:10.1029/2005GL023209.

Griffies, S., and Coauthors, 2008: Coordinated ocean-ice reference experiments (COREs). Ocean Modell., in press.

Gulev, S. K., B. Barnier, H. Knochel, J.-M. Molines, and M. Cottet, 2003: Water mass transformation in the North Atlantic and its impact on the meridional circulation: Insights from an ocean model forced by NCEP/NCAR reanalysis surface fluxes. J. Climate, 16, 3085-3110.

Haine, T., C. Böning, P. Brandt, J. Fischer, A. Funk, D. Kieke, and M. Kvaleberg, and E. Rhein, 2008: North Atlantic deep water transformation in the Labrador Sea, recirculation through the subpolar gyre, and discharge to the subtropics. Arctic-Subarctic Ocean Fluxes, R. R. Dickson, Eds., Springer, 653-7010.

Häkkinen, S., 1999: Variability of the simulated meridional heat transport in the North Atlantic for the period 1951-1993. J. Geophys. Res., 104, 10 991-11 008.

Hirschi, J., J. Baehr, J. Marotzke, J. Stark, S. Cunningham, and 
J.-O. Beismann, 2003: A monitoring design for the Atlantic meridional overturning circulation. Geophys. Res. Lett., 30, 1413, doi:10.1029/2002GL016776.

Houghton, J. T., Y. Ding, D. J. Griggs, M. Noguer, P. J. van der Linden, X. Dai, K. Maskell, and C. A. Johnson, Eds., 2001: Climate Change 2001: The Scientific Basis. Cambridge University Press, $881 \mathrm{pp}$.

Houghton, R. W., and M. H. Visbeck, 2002: Quasi-decadal salinity fluctuations in the Labrador Sea. J. Phys. Oceanogr., 32, 687701.

Hourdin, F., and A. Armengaud, 1999: The use of finite-volume methods for atmospheric advection of trace species: Part I: Test of various formulations in a general circulation model. Mon. Wea. Rev., 127, 822-837.

Jayne, S. R., and J. Marotzke, 2001: The dynamics of ocean heat transport variability. Rev. Geophys., 39, 385-411.

Johnson, H. L., and D. P. Marshall, 2002: Localization of abrupt change in the North Atlantic thermohaline circulation. Geophys. Res. Lett., 29, 1083, doi:10.1029/2001GL014140.

Kalnay, E., and Coauthors, 1996: The NCEP/NCAR 40-Year Reanalysis Project. Bull. Amer. Meteor. Soc., 77, 437-471.

Knight, J. R., R. J. Allan, C. K. Folland, M. Vellinga, and M. E. Mann, 2005: A signature of persistent natural thermohaline circulation cycles in observed climate. Geophys. Res. Lett., 32, L20708, doi:10.1029/2005GL024233.

Kraus, E. B., and J. S. Turner, 1967: A one-dimensional model of the seasonal thermocline II: The general theory and its consequences. Tellus, 19, 98-105.

Lab Sea Group, 1998: The Labrador Sea deep convection experiment. Bull. Amer. Meteor. Soc., 79, 2033-2058.

Large, W. G., and S. G. Yeager, 2004: Diurnal to decadal global forcing for ocean and sea ice models: The data sets and flux climatologies. NCAR Tech. Note NCAR/TN-460+STR, 111 pp.

Latif, M., C. Böning, J. Willebrand, A. Biastoch, J. Dengg, N. Keenlyside, G. Madec, and U. Schweckendiek, 2006: Is the thermohaline circulation changing? J. Climate, 19, 4631-4637.

Lee, T. N., W. Johns, F. Schott, and R. J. Zantopp, 1990: Western boundary current structure and variability east of Abaco, Bahamas at $26.5^{\circ}$ N. J. Phys. Oceanogr., 20, 446-466.

Le Sommer, J., T. Penduff, S. Theetten, G. Madec, and B. Barnier, 2008: How momentum advection schemes influence currenttopography interactions at eddy-permitting resolution. Ocean Modell., 22, in press.

Le Traon, P.-Y., and F. Ogor, 1998: ERS-1/2 orbit improvement using TOPEX/POSEIDON: The $2 \mathrm{~cm}$ challenge. J. Geophys. Res., 103, 8045-8058.

Levitus, S., and T. Boyer, 1994: Temperature. Vol. 4, World Ocean Atlas 1994, NOAA Atlas NESDIS 4, 117 pp.
Lumpkin, R., K. G. Speer, and K. P. Koltermann, 2008: Transport across $48^{\circ} \mathrm{N}$ in the Atlantic Ocean. J. Phys. Oceanogr., 38, $733-752$.

Madec, G., 2006: NEMO ocean engine. Note du Pole de modelisation, Institut Pierre Simon Laplace (ISPL) Tech. Rep. 27, 193 pp.

_, and M. Imbard, 1996: A global ocean mesh to overcome the North Pole singularity. Climate Dyn., 12, 381-388.

Meehl, G., and Coauthors, 2007: Global climate projections. Climate Change 2007: The Physical Science Basis, S. Solomon et al., Eds., Cambridge University Press, 747-846.

Molinari, R. L., R. A. Fine, W. D. Wilson, R. G. Curry, J. Abell, and M. S. McCartney, 1998: The arrival of recently formed Labrador Sea Water in the Deep Western Boundary Current at $26.5^{\circ}$ N. Geophys. Res. Lett., 25, 2249-2252.

Pacanowski, R. C., 1996: MOM 2 version 2, documentation, user's guide and reference manual. Tech. Rep. 3.2, GFDL, 329 pp.

Roemmich, D., and C. Wunsch, 1985: Two trans-Atlantic sections: Meridional circulation and heat flux in the subtropical North Atlantic Ocean. Deep-Sea Res., 32, 619-664.

Schott, F. A., J. Fischer, M. Dengler, and R. Zantopp, 2006: Variability of the Deep Western Boundary Current east of the Grand Banks. Geophys. Res. Lett., 33, L21S07, doi:10.1029/ 2006 GL026563.

Schweckendiek, U., and J. Willebrand, 2005: Mechanisms affecting the overturning response in global warming simulations. J. Climate, 18, 4925-4936.

Semtner, A. J., and R. M. Chervin, 1992: Ocean general circulation from a global eddy-resolving model. J. Geophys. Res., 97, 5493-5550.

Talley, L. D., 2003: Shallow, intermediate, and deep overturning components of the global heat budget. J. Phys. Oceanogr., 33, 530-560.

Treguier, A. M., and Coauthors, 2001: An eddy permitting model of the Atlantic circulation: Evaluating open boundary conditions. J. Geophys. Res., 106, 22 115-22 129.

Visbeck, M., E. Chassignet, R. Curry, T. Delworth, B. Dickson, and G. Krahmann, 2003: The ocean's response to North Atlantic Oscillation variability. The North Atlantic Oscillation: Climate Significance and Environmental Impact, Geophys. Monogr., Vol. 134, Amer. Geophys. Union, 113-146.

Willebrand, J., and Coauthors, 2001: Circulation characteristics in three eddy-permitting models of the North Atlantic. Prog. Oceanogr., 48, 123-161.

Wood, R. A., A. B. Keen, J. F. B. Mitchell, and J. M. Gregory, 1999: Changing spatial structure of the thermohaline circulation in response to atmospheric $\mathrm{CO}_{2}$ forcing in a climate model. Nature, 399, 572-575. 